\title{
Performance Evaluation of Different Sram Cell Structures at DiffERENT TeChNOlOGIES
}

\author{
Sapna Singh ${ }^{1}$, Neha Arora ${ }^{2}$, Meenakshi Suthar ${ }^{3}$ and Neha Gupta ${ }^{4}$ \\ Faculty of Engineering Technology, Mody Institute of Technology and Science, \\ Lakshmangarh, Sikar, INDIA \\ ${ }^{1}$ singh.sana067@gmail.com, ${ }^{2}$ neha241986@gmail.com \\ ${ }^{3}$ meenakshi.suthar32@gmail.com, ${ }^{4}$ wdnehagupta@gmail.com
}

\begin{abstract}
In recent years the demand for low power devices has been increases tremendously. To solve the power dissipation problem, many researchers have proposed different ideas from the device level to the architectural level and above. However, there is no universal way to avoid tradeoffs between power, delay and area, thus designers are required to choose appropriate techniques that satisfy application and product needs. The demand for static random-access memory (SRAM) is increasing with large use of SRAM in System On-Chip and high-performance VLSI circuits. This paper represents the simulation of different SRAM cells and their comparative analysis on different parameters such as Power Supply Voltage, area efficiency etc to enhance the performance. All the simulations have been carried out on BSIM 3V3 90nm, $45 \mathrm{~nm}$ and 32 technology at Tanner EDA tool.
\end{abstract}

\section{KEYWORDS}

CMOS Logic, Low power, Speed, SRAM and VLSI.

\section{INTRODUCTION}

The term memory is usually used as a short hand for physical memory which refers to the actual chips capable handling data. The transistors have been lowered which also contributes to leakage currents and reduces the battery life dramatically. Solutions involving additional transistors, i.e., 8T, and 9T, 10T, Differential 10T have been explored to lower power consumption while reducing these adverse effects in the cell performance. We will therefore look into a couple of these SRAM Cells topologies that allow the analysis and simulations of different parameters at $90 \mathrm{~nm}, 32 \mathrm{~nm}$ and $45 \mathrm{~nm}$ technology successfully on the basis of the power dissipation, speed and their temperature dependence with the area efficiency of the circuit.

\section{LiterATURE REVIEW OF DIFFERENT SRAM CELLS}

\subsection{T SRAM Cell}

In such a case, the SRAM voltage does not scale with technology and could even be increased as variability intensifies. The schematic diagram of 6T SRAM cell is shown in Figure.1 [1]. During read, the WL voltage VWL is raised, and the memory cell discharges either BL (bit line true) or BLB (bit line complement), depending on the stored data on nodes Q and QB. A sense amplifier converts the differential signal to a logic-level output. Then, at the end of the read cycle, the BLs returns to the positive supply rail. During write, VWL is raised and the BLs are forced to either VDD (depending on the data), overpowering the contents of the memory cell. During hold, VWL is held low and the BLs are left floating or driven to VDD.

DOI : $10.5121 /$ vlsic. 2012.3108 


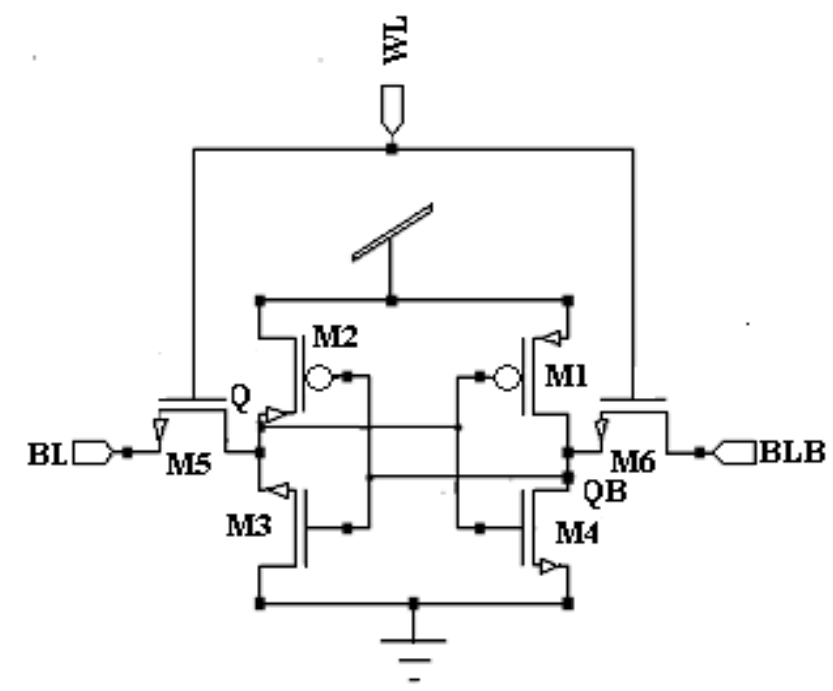

Figure 1. Schematic of 6T SRAM Cell

\subsection{T SRAM Cell}

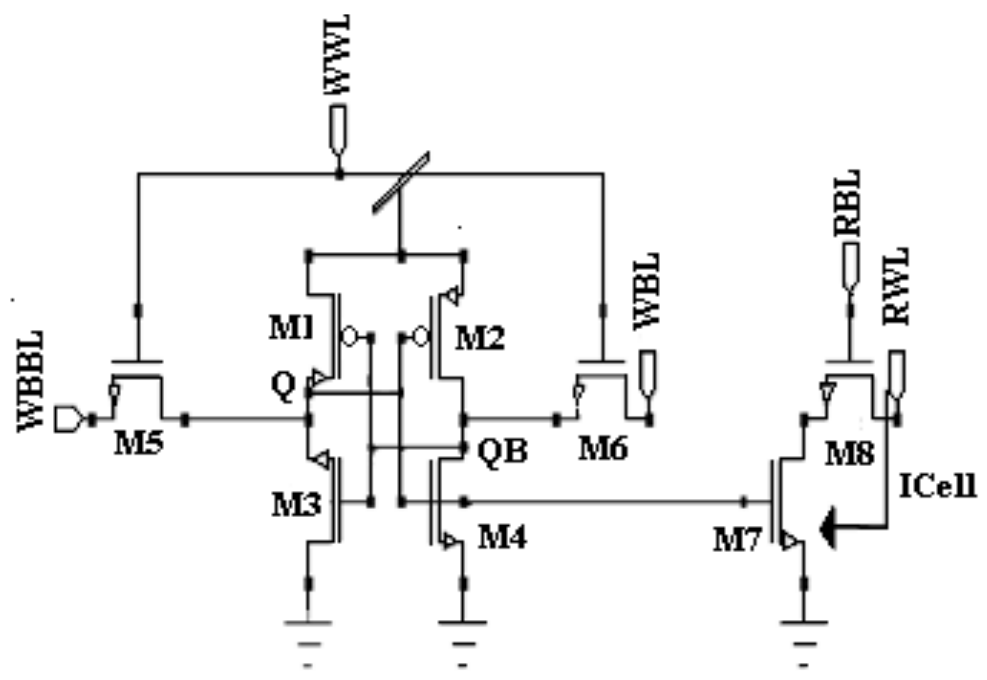

Figure 2. Schematic of 8T SRAM Cell

A dual-port cell (8T-cell) is created by adding two transistors, the read can be entirely decoupled from the write operation in an $8 \mathrm{~T}$ cell by sensing the data through a separate read stack controlled by a separate read wordlines (RWL).The remaining $6 \mathrm{~T}$ portion of the cell is optimized for write, resulting in an overall lower Vmin. Separation of data retention element and data output element means that there will be no correlation between the read SNM Cell and I Cell. Thus, an 8T SRAM design [5] contains a write assist in which a horizontally routed VDD line is collapsed during write. As a result, the bit cell array Vmin is limited by the hold margin. 


\subsection{TSRAM Cell}

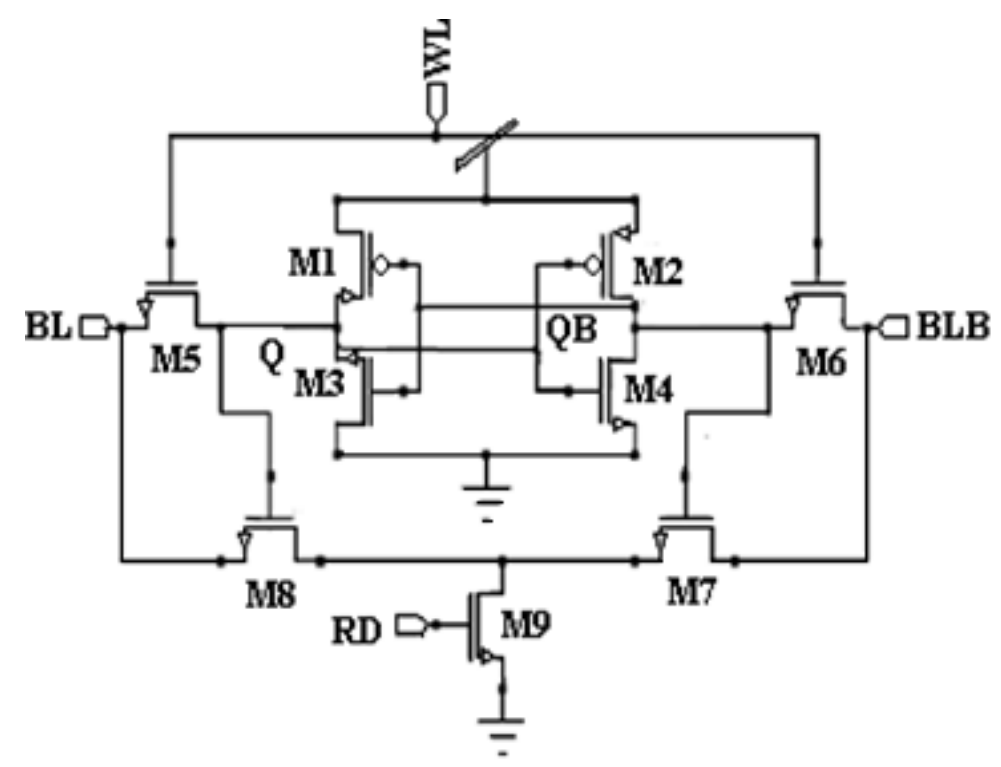

Figure 3. Schematic of 9T SRAM Cell

The schematic of the 9T SRAM cell, for CMOS technology, is shown in Figure.3. The upper subcircuit of the 9T memory circuit is essentially a 6T SRAM cell with minimum sized devices (composed of M3, M4, M5, M6, M1 and M2). The two write access transistors (M5 and M6) are controlled by a write signal (WL). The data is stored within this upper memory sub-circuit. The lower sub circuit of the new cell is composed of the bit-line access transistors (M7 and M8) and the read access transistor (M9). The operations of M7 and M8 are controlled by the data stored in the cell. M9 is controlled by a separate read signal (RD) [7].The 9T SRAM cell completely isolates the data from the bit lines during a read operation.

\subsection{T SRAM Cell}

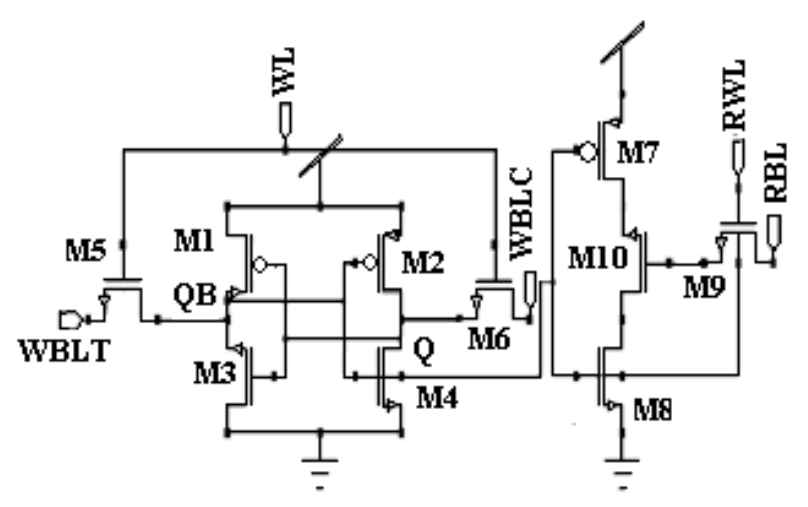

Figure.4 Schematic of 10T SRAM Cell

Figure.4 shows the schematic of the 10T sub threshold bit cell.[6] Transistors are identical to a 6T bit cell except that the source of M1 and M2 tie to a virtual supply voltage rail Vdd. Write access to the bitcell occurs through the write access transistors, M5 and M6, Transistors from the write bitlines, WBLT and WBLC. Transistors M8 through M10 implement a buffer used for reading. 
Read access is single-ended and occurs on a separate bitline, RBL, which is precharged to prior to read access. The wordline for read also is distinct from the write wordline. One key Advantage to separating the read and write wordlines and bit lines is that a memory using this bit cell can have distinct read and write ports.

\subsection{Modified 10T SRAM Cell}

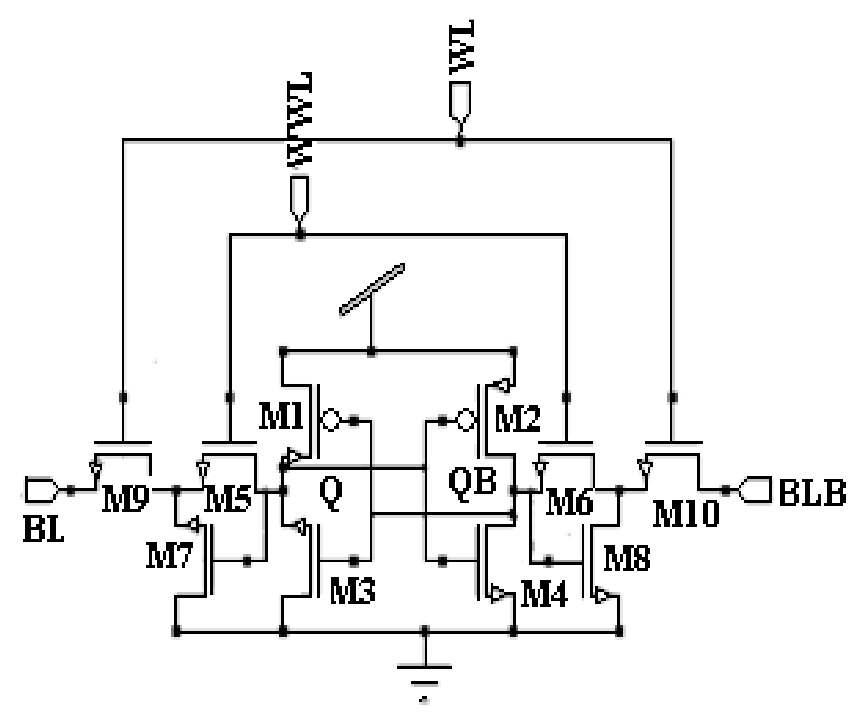

Figure.5 Schematic of Modified 10T SRAM Cell

Figure.5 shows a schematic of a 10T SRAM with differential read bitlines (BL and BLB) [6].Two NMOS transistors (M9 and M7) for the RBL and the other additional NMOS transistors (M8 and M10) for BLB are appended to the 6T SRAM. The 10T cell permits bit interleaving and exhibits superior sense margin with a differential read path based on a DCVSL (differential cascade voltage-switch-logic level) structure at the column periphery [8].There is a performance degradation from stacked transistors that requires boosted WL voltages, but BL leakage is reduced at the same time.

\section{Simulation Performance and Analysis}

All the circuits have been simulated using BSIM $3 \mathrm{~V} 390 \mathrm{~nm}, 45 \mathrm{~nm}$ and 32nm technology on Tanner EDA tool with supply voltage ranging. To make the impartial testing environment all the circuits has been simulated on the same input patterns. Figure 6-Figure17 shows comparative analysis of the circuits stated above at $90 \mathrm{~nm}, 45 \mathrm{~nm}$ and $32 \mathrm{~nm}$ technology. The simulation results reveal that 10T Modified SRAM Cell at 90nm and 45nm technology and 10T SRAM Cell at $32 \mathrm{~nm}$ technology shows always best performance for the range of power consumption, operating frequency and temperature $[3,9]$. 
International Journal of VLSI design \& Communication Systems (VLSICS) Vol.3, No.1, February 2012

\subsection{Simulation of different SRAM cells at 90nm technology.}

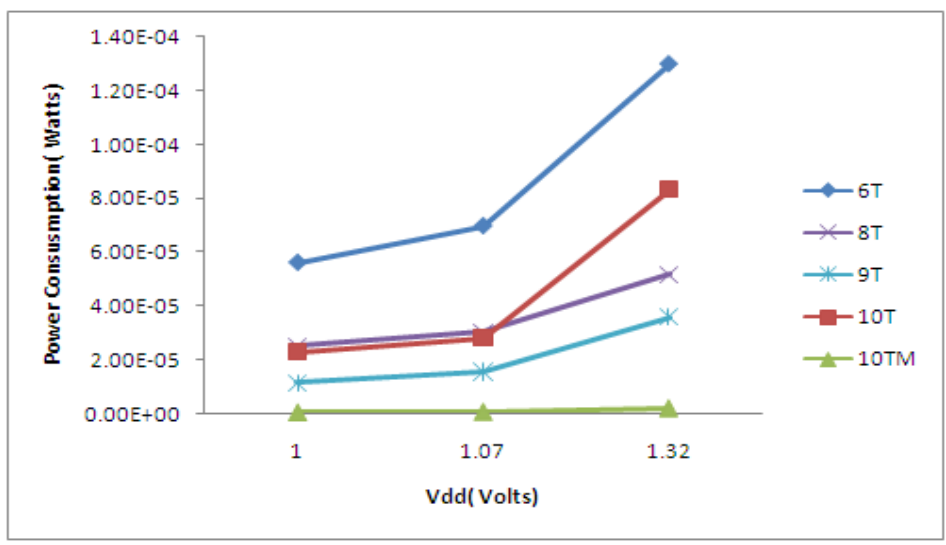

Figure 6. Power Consumption vs. Vdd for Different SRAM Cells

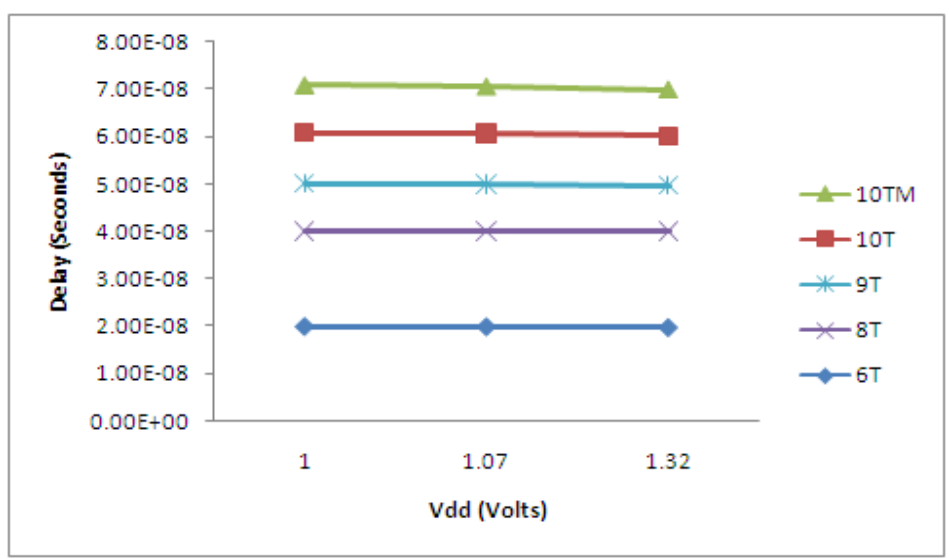

Figure 7. Delay vs. Vdd for Different SRAM Cells

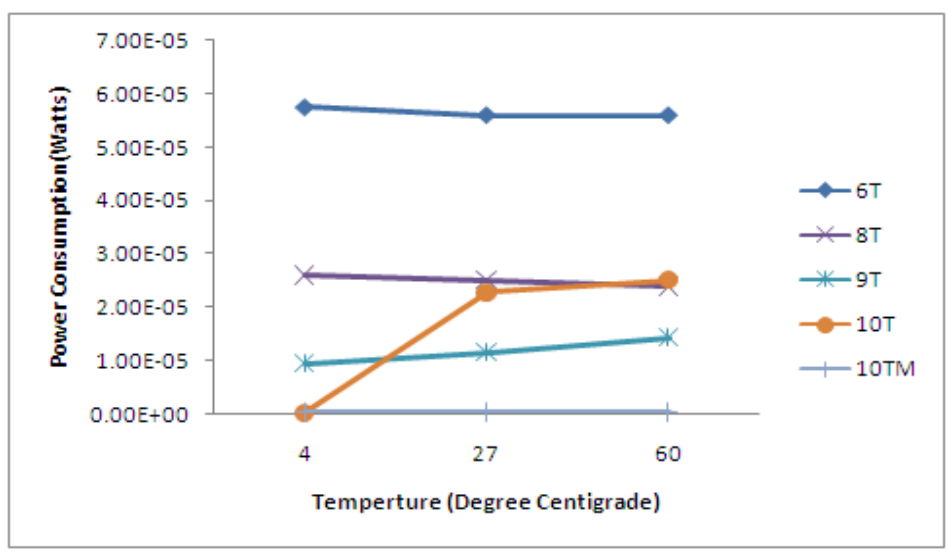

Figure 8. Power Consumption vs. Operating Temperature for Different SRAM Cells. 
International Journal of VLSI design \& Communication Systems (VLSICS) Vol.3, No.1, February 2012

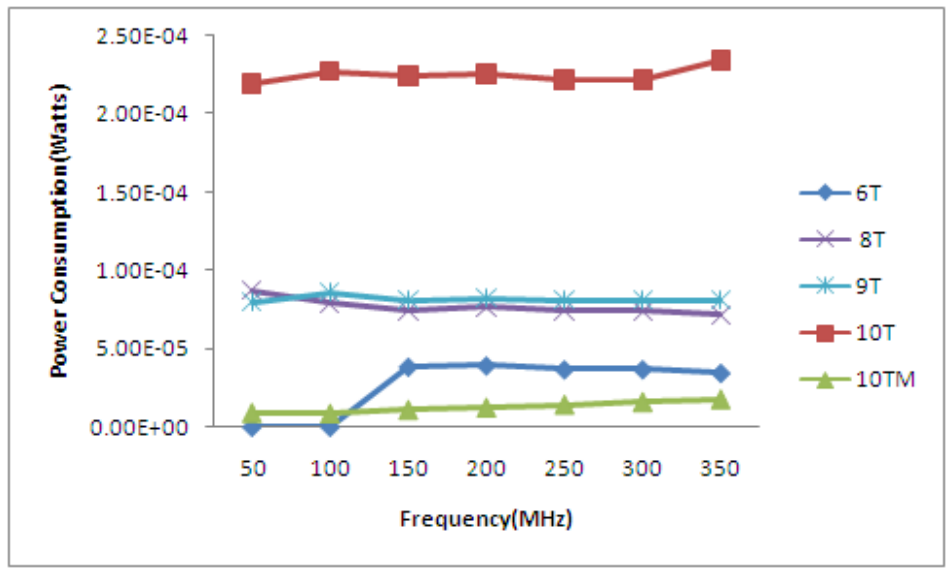

Figure 9. Power Consumption vs. Operating Frequency for Different SRAM Cells

\subsection{Simulation of different SRAM cells at $45 \mathrm{~nm}$ technology.}

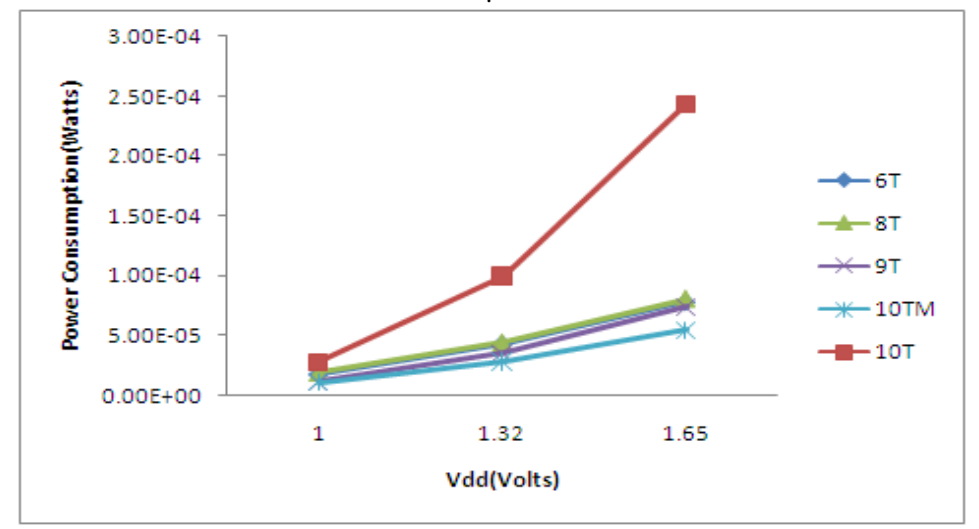

Figure 10. Power Consumption vs. Vdd for Different SRAM Cells

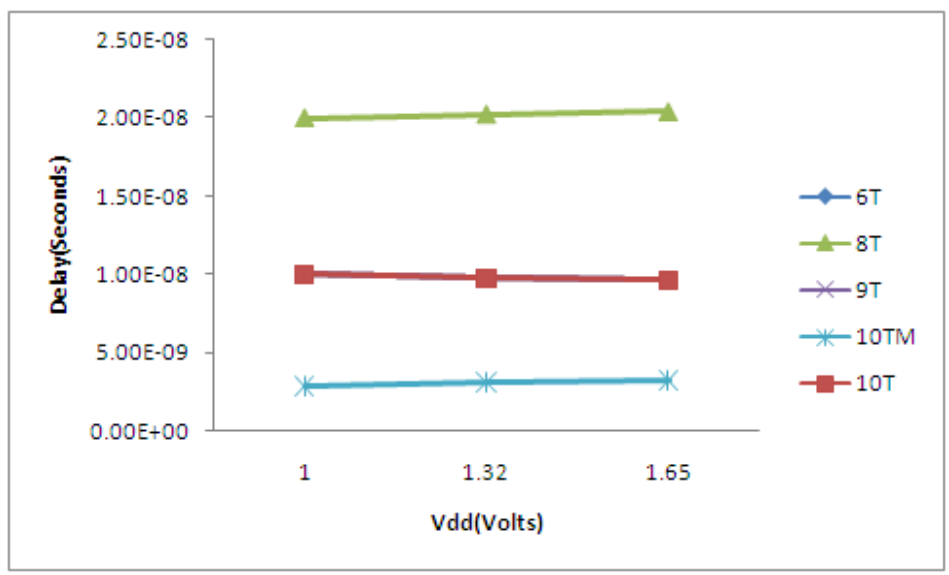

Figure 11. Delay vs. Vdd for Different SRAM Cells 
International Journal of VLSI design \& Communication Systems (VLSICS) Vol.3, No.1, February 2012

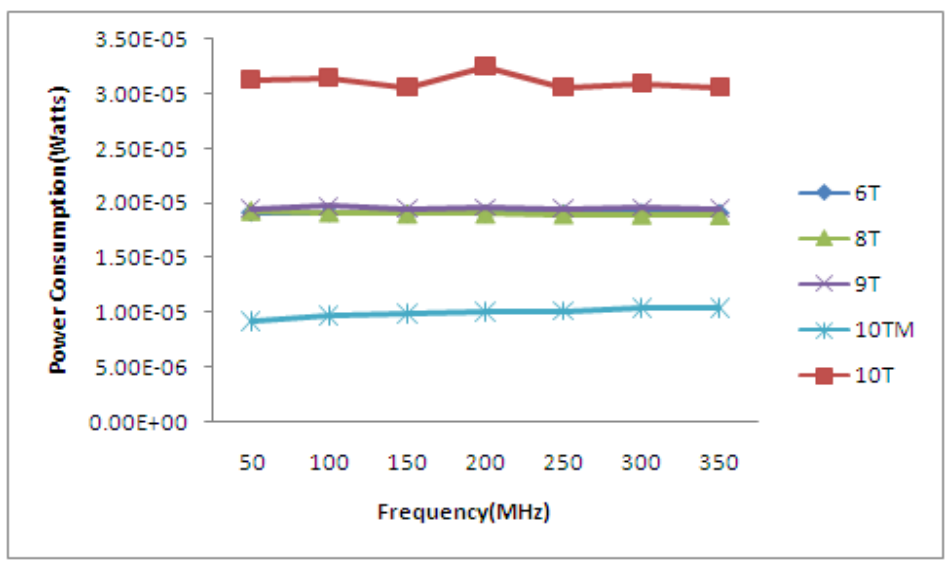

Figure 12. Power Consumption vs. Operating Frequency for Different SRAM Cells.

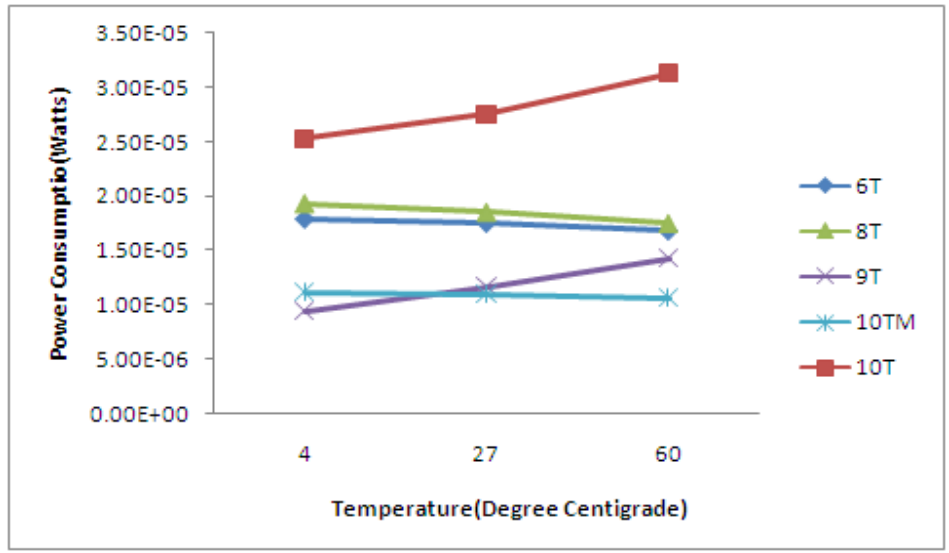

Figure 13. Power Consumption vs. Operating Temperature for Different SRAM Cells

\subsection{Simulation of different SRAM cells at 32nm technology.}

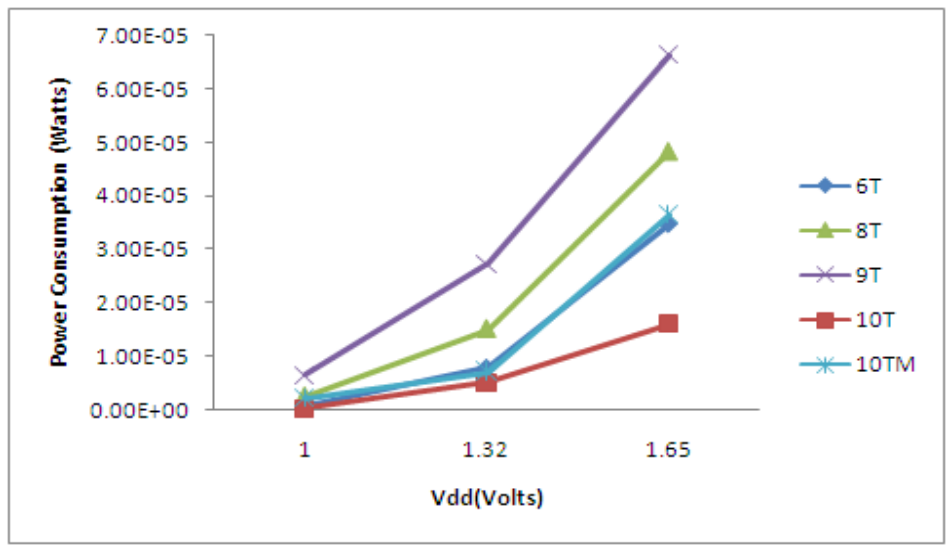

Figure 14. Power Consumption vs. Vdd for Different SRAM Cells 
International Journal of VLSI design \& Communication Systems (VLSICS) Vol.3, No.1, February 2012

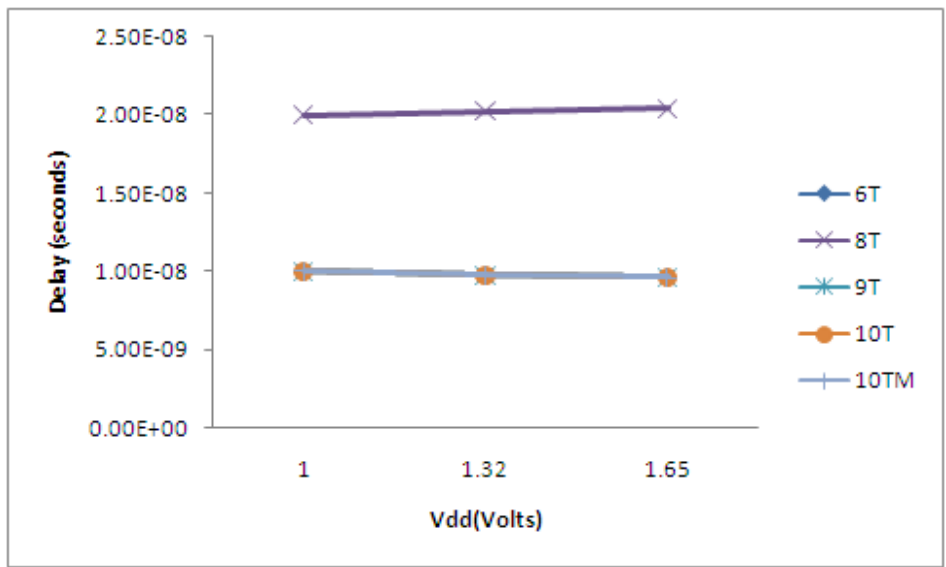

Figure 15. Delay vs. Vdd for Different SRAM Cells

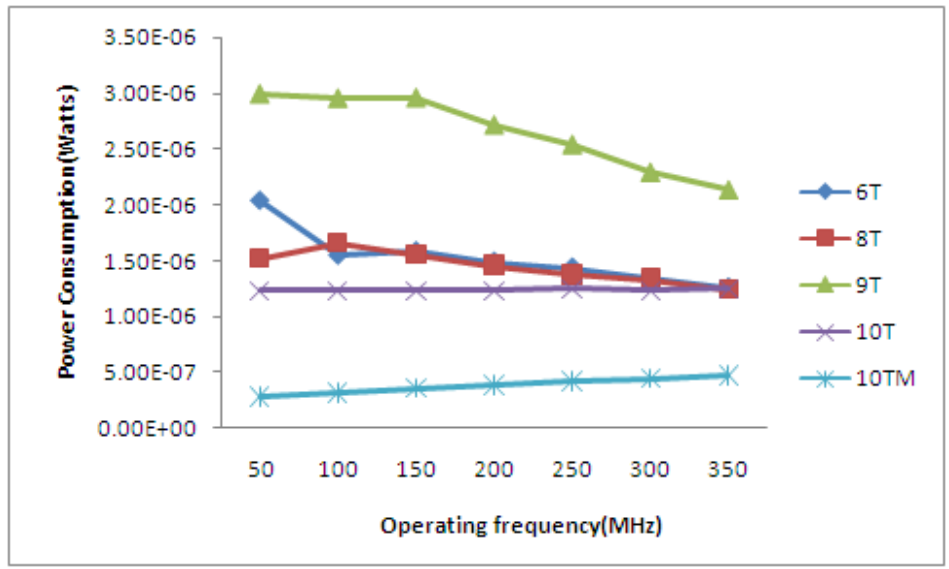

Figure 16. Power Consumption vs. Operating Frequency for Different SRAM Cells.

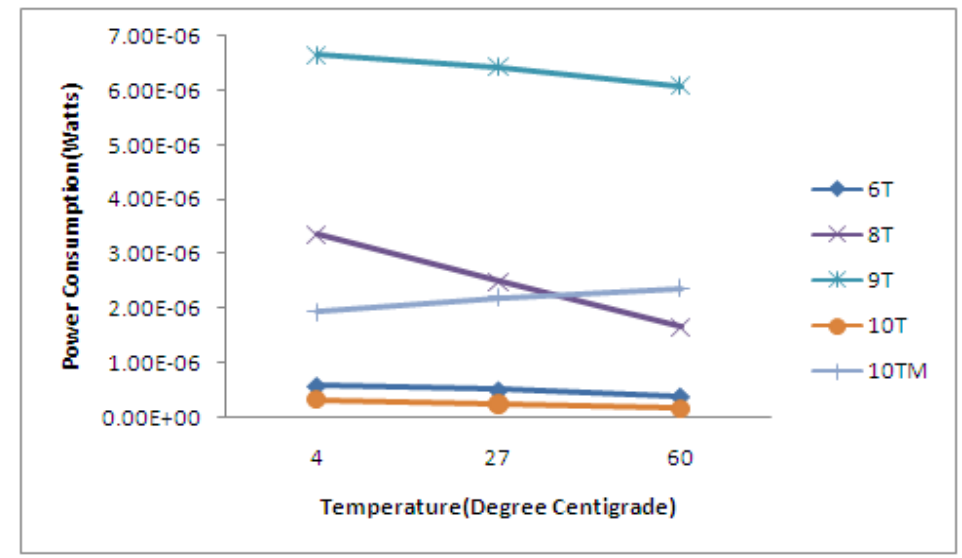

Figure 17. Power Consumption vs. Operating Temperature for Different SRAM Cells.

\section{ObServations}

The following are the observations of power delay product of different SRAM cells at different technologies with supply voltage ranging. 
International Journal of VLSI design \& Communication Systems (VLSICS) Vol.3, No.1, February 2012

\begin{tabular}{|c|c|c|c|}
\hline \multirow{2}{*}{$\begin{array}{c}\text { Different } \\
\text { SRAM } \\
\text { Cells }\end{array}$} & \multicolumn{3}{|c|}{ Power Delay Product(watts-seconds) } \\
\cline { 2 - 4 } & Vdd=1v & Vdd=1.07v & Vdd=1.32v \\
\hline $\mathbf{6 T}$ & $1.12 \mathrm{E}-12$ & $1.39 \mathrm{E}-12$ & $2.57 \mathrm{E}-12$ \\
\hline $\mathbf{8 T}$ & $5.03 \mathrm{E}-13$ & $6.06 \mathrm{E}-13$ & $1.05 \mathrm{E}-12$ \\
\hline $\mathbf{9 T}$ & $1.16 \mathrm{E}-13$ & $1.56 \mathrm{E}-13$ & $3.49 \mathrm{E}-13$ \\
\hline $\mathbf{1 0 T}$ & $2.46 \mathrm{E}-13$ & $3.00 \mathrm{E}-13$ & $8.60 \mathrm{E}-13$ \\
\hline $\mathbf{1 0 T M}$ & $\mathbf{3 . 0 4 E}-15$ & $\mathbf{4 . 8 5 E}-15$ & $\mathbf{1 . 7 8 E}-14$ \\
\hline
\end{tabular}

Table 1. Power Delay Product comparison of different SRAM cells at $90 \mathrm{~nm}$ technology.

\begin{tabular}{|c|c|c|c|}
\hline \multirow{2}{*}{$\begin{array}{c}\text { Different } \\
\text { SRAM } \\
\text { Cells }\end{array}$} & \multicolumn{3}{|c|}{ Power Delay Product(watts-seconds) } \\
\cline { 2 - 4 } & Vdd=1v & Vdd=1.32v & Vdd=1.65v \\
\hline $\mathbf{6 T}$ & $1.75 \mathrm{E}-13$ & $4.19 \mathrm{E}-13$ & $7.05 \mathrm{E}-13$ \\
\hline $\mathbf{8 T}$ & $3.70 \mathrm{E}-13$ & $9.72 \mathrm{E}-13$ & $1.65 \mathrm{E}-12$ \\
\hline $\mathbf{9 T}$ & $1.16 \mathrm{E}-13$ & $3.49 \mathrm{E}-13$ & $7.11 \mathrm{E}-13$ \\
\hline $\mathbf{1 0 T}$ & $2.75 \mathrm{E}-13$ & $9.74 \mathrm{E}-13$ & $2.34 \mathrm{E}-13$ \\
\hline $\mathbf{1 0 T M}$ & $\mathbf{3 . 0 8 E}-13$ & $\mathbf{8 . 5 4 E}-13$ & $\mathbf{1 . 7 4 E}-13$ \\
\hline
\end{tabular}

Table 2. Power Delay Product comparison of different SRAM cells at $45 \mathrm{~nm}$ technology.

\begin{tabular}{|c|c|c|c|}
\hline Different $\begin{array}{c}|c| \\
\text { SRAM } \\
\text { Cells }\end{array}$ & \multicolumn{3}{|c|}{ Power Delay Product(watts-seconds) } \\
\cline { 2 - 4 } & Vdd=1v & Vdd=1.32v & Vdd=1.65v \\
\hline $\mathbf{6 T}$ & $4.97 \mathrm{E}-15$ & $7.55 \mathrm{E}-14$ & $3.33 \mathrm{E}-13$ \\
\hline $\mathbf{8 T}$ & $5.00 \mathrm{E}-14$ & $3.05 \mathrm{E}-12$ & $9.85 \mathrm{E}-13$ \\
\hline $\mathbf{9 T}$ & $6.43 \mathrm{E}-14$ & $2.66 \mathrm{E}-13$ & $6.37 \mathrm{E}-13$ \\
\hline $\mathbf{1 0 T}$ & $\mathbf{2 . 5 2 E}-15$ & $\mathbf{4 . 9 1 E}-14$ & $\mathbf{1 . 5 7 E}-13$ \\
\hline $\mathbf{1 0 T M}$ & $2.21 \mathrm{E}-14$ & $7.02 \mathrm{E}-14$ & $3.50 \mathrm{E}-13$ \\
\hline
\end{tabular}

Table 3. Power Delay Product comparison of different SRAM cells at $32 \mathrm{~nm}$ technology.

\section{Simulation RESUltS}

Figure 18-Figure 22 shows output waveforms of different SRAM cell structures stated above at $90 \mathrm{~nm}, 45 \mathrm{~nm}$ and $32 \mathrm{~nm}$ technology. 
International Journal of VLSI design \& Communication Systems (VLSICS) Vol.3, No.1, February 2012

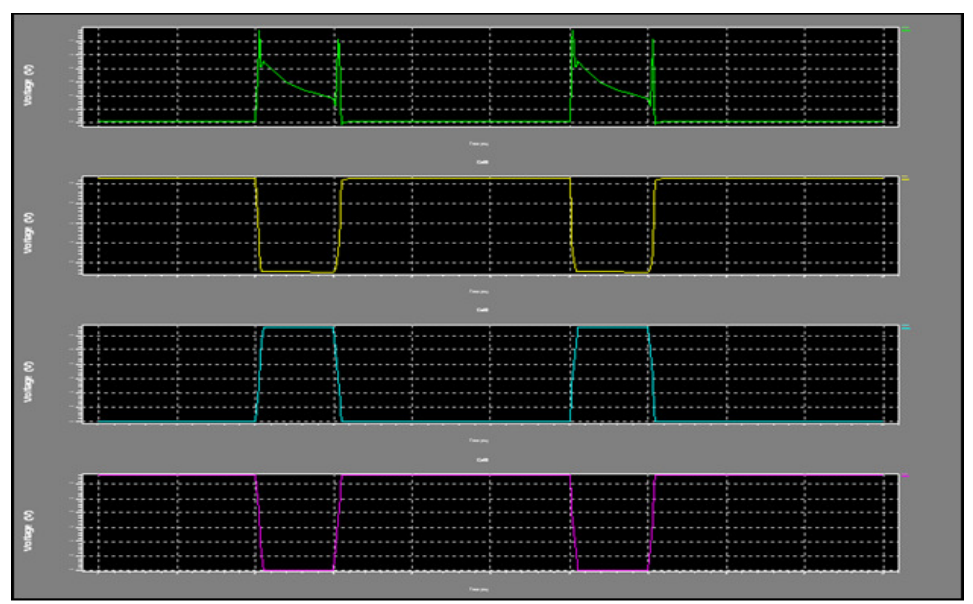

Figure 18. Output waveform of 6T SRAM cell.

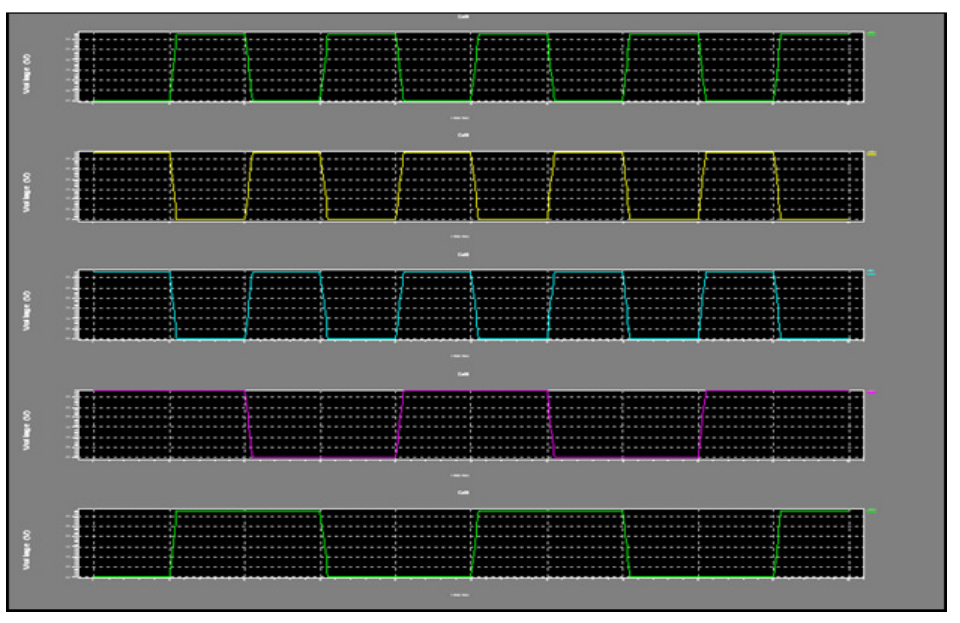

Figure 19. Output waveform of 8T SRAM cell

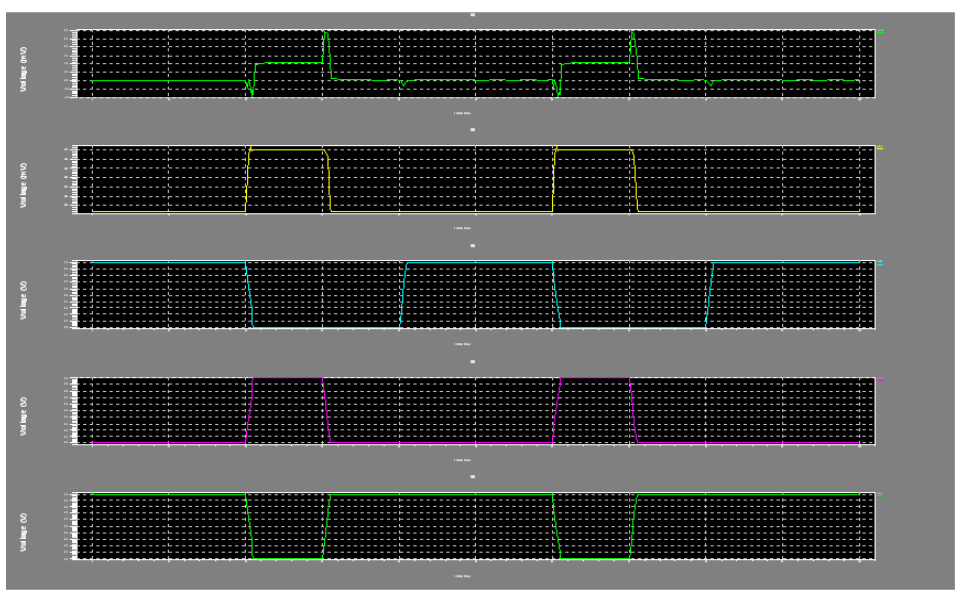

Figure 20.Output waveform of 9T SRAM cell 


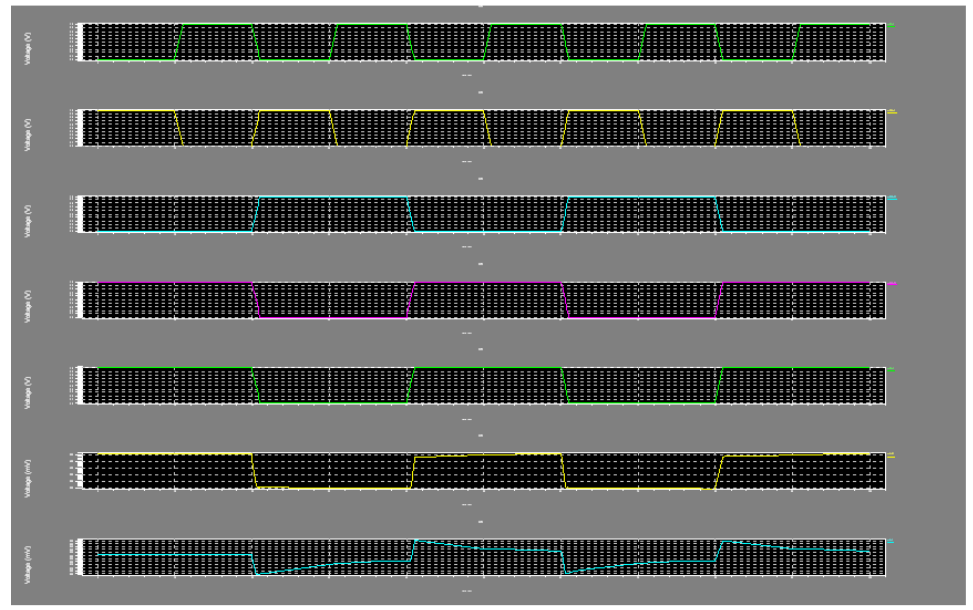

Figure 21.Output waveform of 10T SRAM cell

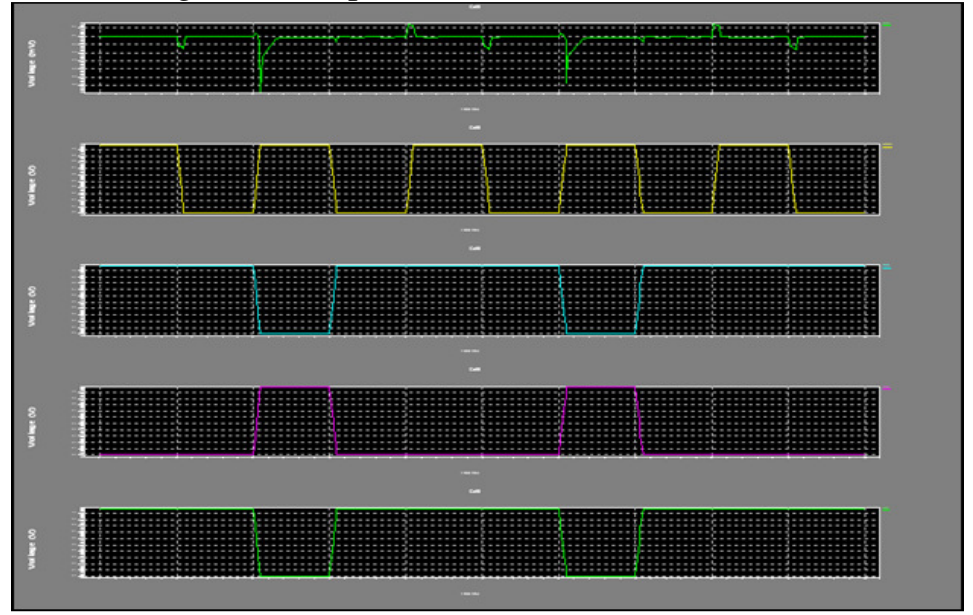

Figure 22.Output waveform of Modified 10T SRAM cell

\section{CONCLUSION}

A conclusion section must be included and should indicate clearly, the most efficient technique to reduce the power dissipation is the reduction of the supply voltage. The power dissipation reduction in SRAMs is not only due to power supply voltage reduction, but also to operating frequency and temperature. All the above figures depicts that 10T Modified SRAM cell at 90nm and $45 \mathrm{~nm}$ technology and 10T SRAM cell at $32 \mathrm{~nm}$ technology shows better performance for the range of frequency and temperature among all the other design approaches for SRAM cell. This paper tries to find out an efficient SRAM memory cell in both the aspects power consumption and speed in terms of power delay product at different technologies.

\section{ACKNOWLEDGEMENT}

We would like to sincerely thank Prof. B.P Singh, Head of Department of Electronics \& Communication, Mody Institute of Technology and Science, Lakshmangarh who inspired us to do this work. In addition we would like to thank Prof P.K Das, Dean, Faculty of Engineering, Mody Institute of Technology and Science for providing us resources to carry out our work. 
International Journal of VLSI design \& Communication Systems (VLSICS) Vol.3, No.1, February 2012

\section{REFERENCES}

[1] Jawar Singh, Dhiraj K.Pradhan," A single ended 6T SRAM cell design for ultra low voltage applications", IEICE Electronic Express, 2008, pp-750-755.

[2] Kang, Sung-Mo, Leblebici and Yusuf (1999), "CMOS digital integrated circuits analysis and design", McGraw-Hill International Editions, Boston, 2nd Edition.

[3] C-T. Chu, X. Zhang, L. He and T. Jing, "Temperature aware microprocessor floorplanning considering application dependent power load", in Proc. of ICCAD, 2007, pp. 586-589.

[4] Narender Hachette and Nagarajan Ranganathan, "LECTOR: A technique for leakage reduction in CMOS circuits," IEEE Trans., on VLSI Systems, vol. 12, No.2, Feb 2004.

[5] Chang, L. Montoye, R.K. Nakamura, Y.Batson, K.A.Eickemeyer, R.J.Dennard, R.H. Haensch, W.Jamsek, D, “An 8T-SRAM for variability tolerance and low-voltage operation in highperformance caches”, Solid-State Circuits, IEEE Journal vol. 43, April 2008, Issue 4, pp-956-963.

[6] Zhiyu Liu, Volkan Kursun, “ Characterization of a novel nine transistor SRAM cell”, IEEE Transactions on Very Large Scale Integration Systems, vol.46, Issue 4,April 2008.pp-488-492.

[7] Koichi Takeda, "A read static noise margin free SRAM cell for low Vdd and high speed applications", Solid-State Circuits, IEEE Journal vol. 41, Jan.2006, Issue 1, pp.113-121.

[8] Hiroki Noguchi, "Which is the best dual port SRAM in 45nm process technology? 8T, 10T single end and 10T differential" Renesas Technology corporation, 2008.

[9] S. Dutta, S. Nag, K. Roy, "ASAP: A transistor sizing tool for speed, area, and power optimization of static CMOS circuits", IEEE International Symposium on Circuits and Systems, pp. 61-64, June, 1994.

[10] Rajshekhar Keerthi ,Henry Chen, "Stability and static noise margin analysis of low power SRAM" IEEE International Instrumentation \& Measurement Technology Conference, Victoria Canada, May 2008,pp-1541-1544.

[11] A. P. Chandrakasan, S. Sheng, and R. W. Brod ersen, "Low-power CMOS digital design." IEEE J. Solid-State Circ., vol. 27, no. 4, pp. 473-484, Apr. 1992.

[12] J.Rabaey, "Digital Integrated Circuits, A Design Perspective", Prentice Hall, Upper Saddle River,NJ, 1996. 


\section{Authors}

Sapna Singh received her B.Tech degree in Electronics and Communication Engineering from Kumaon Engineering College, Dwarahat in 2010 and presently pursuing M.Tech VLSI Design in Mody Institute of Technology and Science, Lakshmangarh. Her research interests are low power vlsi design and analog and digital integrated circuit design.

Neha Arora was born in 1986. She received the B.E. degree in Electronics and Communication engineering from the Reputed College of Rajasthan University, India, in 2007, and recently completed the academics of M.Tech in VLSI Design from Faculty of Engineering \& Technology, Mody Institute of Technology and Science in 2010. To share the knowledge that she gained and to show her abilities in teaching profession, she started to work as a lecturer in 2007. After gaining the experience of two years, she was promoted to Assistant Professor in 2009 with the Department of Electronics and Communication Engineering, at Mody Institute of Technology and Science (Deemed University).Her current research interests include low-voltage, low power, and high-performance integrated circuit design and simulation of Very large scale integrated circuits. She has more than 30 publications in international journals and Conferences in the areas of high performance integrated circuits and emerging semiconductor Technologies.

Meenakshi Suthar received her B.Tech degree in Electronics and Communication Engineering from Marudhar Engineering College, Bikaner in 2010, and presently pursing M.Tech VLSI Design in Mody Institute of Technology and Science, Lakshmangarh. Her research interests are analog integrated circuit design and analog communication systems.

Neha Gupta received her B.Tech degree in Electronics and Communication Engineering from Mody institute of Technology and Science, Lakshmangarh in 2009, and presently pursuing M.Tech VLSI Design in Mody Institute of Technology and Science, Lakshmangarh. Her research interests are analog integrated circuit design and high performance analog circuits.
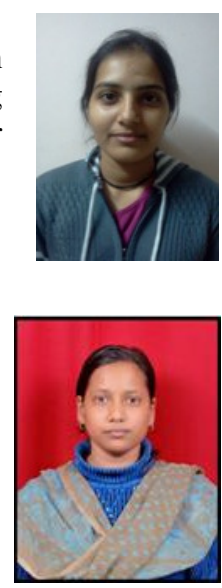